Integritas 4.4 (Fall 2014), pp. 21-23.

doi: 10.6017/integritas.v4i4p21

\title{
Summary of Roundtable Conversation
}

The animated response to Kevin Hughes and Marian Díaz began with a question about the Latin American bishops' experience of encuentro, "encounter," which Díaz described as a shared process of reflection and discernment, and which provides models for the kind of role that Catholic academics might have in the world. Another participant pointed out that the practical application of these models can be difficult, though: students still learning how to engage with people from very different cultural backgrounds will struggle, and must be encouraged to develop practices of reflection rooted in humility.

Several wondered what the challenges around developing cultural fluency meant for the pedagogical process and the curriculum itself. Kevin Hughes suggested beginning with interpersonal relations: the lived experience of faculty and staff as points-ofdeparture for cultivating friendships between institutions in different countries. Another participant highlighted Hughes's exploration of the dangers of cultural tourism, remarking that commitment to study abroad opportunities has to be rooted in the Catholic social tradition, and means that the university as a whole must be willing to be transformed by its relationship with institutions in other countries. A third participant underscored the importance of language; specifically, the need for students to apprentice themselves to native speakers in a host country in order to develop the cultural fluency that comes only with learning a new language. Finally, someone pointed to the multiple “x studies" programs (women's; African; Asian; Catholic; Islamic; etc.) that offer students opportunities to immerse themselves in many courses exploring a culture. Such programs, especially for students who do not come from the groups under study, can be transformative. In all these observations about curriculum, one participant noted, there is an implicit commitment to the way that liberal education is a form of resistance against an unreflective economic globalization.

Another participant underscored the rapid growth in international populations on Catholic campuses in the United States, but noted that in many cases this population includes "full pay" students from wealthy families in China, Saudi Arabia, and elsewhere. Often they end up segregated from other students because of their economic and cultural differences. Taking this observation a step further, he speculated that it would be possible to finance an entire university operation by bringing in more such students - the richest of the rich-but that fundamental questions of mission would 
arise. In contrast, some U.S. colleges and universities are hoping to build scholarships for students from Catholic (often Jesuit) secondary schools around the world.

A key question, reflected one participant, is about the notion of cosmopolitanism and the danger of it being a kind of rootlessness. What, this participant asked, can Catholic tradition offer for a more enriching kind of world citizenship? Hughes pointed back to Matteo Ricci as a model for holding onto a theocentrism still open toward otherness. Holding onto mission while seeking a cosmopolitan ideal is a challenge that will involve-as Ricci discovered-reimagining what is at the root of Catholic mission. Díaz pointed out that such a complex conversation reflects the complexity of university life itself. It means, among other things, creating spaces for conversation such that the rich learn from the poor, and the privileged learn from the suffering.

In response to this idea, another participant pointed to a model she sees working on her campus. Students preparing for study and immersion experiences in Uganda and Ghana spend a good amount of time getting to know their fellow students from those countries, sharing meals and growing in friendship. The African students have the opportunity to share some of their wisdom in ways that help the American students prepare for their experience abroad.

Another participant, responding to the recommendation of the book Authentic Cosmopolitanism by R.J. Snell and Steven D. Cone, ${ }^{\mathrm{I}}$ which pushes back against the charge of rootless cosmopolitanism by proposing a rich account of the knowing, loving subject, suggested that there are important resources to draw from Catholic ecclesiology. She narrated two anecdotes which pointed to these resources. The first was from her experience leading her college's program abroad, where students experienced frustration with the differences in efficiency. Responding to the professor's invitation to regard these differences as embedded in the guest-host relationship, they joked about every bad experience in the foreign city being the result of "getting hosted." In contrast, she related how moved her students were by the experience of being with hundreds of other Catholics and feeling a deep sense of kinship, a connection by virtue of their shared communion. Her point was that Catholicism proposes an alternate model of relationship that our campuses would do well to reflect upon and offer to students.

The challenge, several people noted, is that students are coming from very different places. One observed that in study abroad experiences especially, there seems to be a certain script which says that you must move quickly through a host of recognizable experiences-like visiting the Eiffel Tower, for example-and post pictures on Instagram. Another noted that the virtual world has fostered virtual, incomplete notions of solidarity. Students may have friends all over the world who evince a simulacrum of friendship because they happen to have shared interest. He called for a return to spiritual practices such as silence that counteract the fast pace and rootlessness of the existing student script.

1 R.J. Snell and Steven D. Cone, Authentic Cosmopolitanism: Love, Sin, and Grace in the Christian University (Eugene: Pickwick Publications, 2013). 
Yet the challenge is rooted in the fact that there are real differences that make friendship, solidary, and communion difficult. One person told the story of the parent of a student, a professor in Columbia's Art History department, whose teaching changed as a result of having many Chinese students in class. Their unfamiliarity with figures like Jesus or Judas made it very difficult to teach Western art. Another person described conversations with undocumented students at his university, students who were invited to participate in a conference but could not, simply because they lacked documents needed to board an airplane. A third related the difficulty he experienced with a student from another country who, upon being asked to rewrite a paper, was distressed at having lost face.

What is needed, several participants averred, is the development of a kind of Catholic cosmopolitanism different from those forms that are rooted in some form of imperial power. Hughes recalled the lessons of missiology and the negative influences of such power, and pointed to the original Stoic notion of cosmopolitanism as being easy for someone like Marcus Aurelius, who owned the world in which he claimed citizenship. A Catholic form of cosmopolitanism would include, one person noted, the young men and women on our campuses who are members of religious orders in different parts of the world-often habited, reflecting practices and attitudes that some in the United States consider remnants of a pre-Vatican II Church. Yet the enthusiasm and witness of these young men and women is unimpeachable. At present, we in the United States are educating these leaders in the Church; but they too teach us what it means to be faithful. And our shared participation in the Body of Christ is a very different notion of world citizenship that we can offer to our students. 
